\title{
POESÍA Y REALIDAD, ENCUENTROS \\ Y DESENCUENTROS DEL LENGUAJE
}

\author{
Luis Arturo Restrepo \\ Universidad de Antioquia \\ luisarturo.restrepo@gmail.com \\ Recibido: 14/08/2018 - Aceptado: 15/11/2018 \\ doi.org/10.17533/udea.lyl.n75a08
}

\begin{abstract}
Resumen: En el artículo se propone como tema central la relación intrínseca entre la literatura y la realidad, centrando dicha discusión en los alcances y límites del lenguaje. Aunque se parte de la literatura en general, se establecen relaciones teóricas y artísticas puntuales sobre la poesía, entendida según la propuesta de Gadamer como "obra de arte verbal". El artículo también aborda dichas problemáticas desde algunos postulados teóricos de los estudios culturales, la filosofía y la lingüística, así como de algunos poetas y escritores, con la intención de proponer diferentes lecturas y problematizarlas a la luz de la poesía misma.
\end{abstract}

Palabras clave: Literatura; realidad; poesía; ficción; lenguaje; representación.

\section{POETRY AND REALITY, AGREEMENTS AND DISAGREEMENTS OF LANGUAGE}

\begin{abstract}
The article proposes as a main topic the intrinsic relation between literature and reality, focusing such discussion on language; that is, on its reach and limitations, its probabilities and restrictions. Even though the starting point is literature in general, punctual theoretical and artistic relations on poetry are established, this time, from Gadamer's "verbal work of art" proposal. The article also approaches such difficulties from some theoretical postulates of social studies, philosophy, linguistics and some poets and writers. All this, with the intention of proposing different readings to be discussed from poetry's viewpoint.
\end{abstract}

Keywords: Literature; Reality; Poetry; Fiction; Language; Representation.

1 Variamos el término empleado por Antonio Gómez Ramos en su traducción de Poetizar e interpretar (Gadamer, 2006, p. 77). La expresión original en Ästhetik und Poetik (Gadamer, 1993, p. 21) es das sprachliche Kunstwerk que más bien podría traducirse como "la obra de arte verbal" [n.e.]. 


\section{Introducción}

A hablar de la relación existente entre la literatura y la realidad, es indispensable Aincluir en esta pareja, ya de por sí bien problemática, el carácter de la representación, entendido aquí como la producción de sentido por medio del lenguaje y en su naturaleza de intercambio en relación con la cultura. Para iniciar, retomamos a Stuart Hall (1997), quien, desde los estudios culturales y de la mano de la lingüística, entiende que la representación es la instancia comunicativa que nos posibilita como sociedad el intercambio del lenguaje.

Así pues, lo que hace el lenguaje, en su producción de sentido, es servir de mediador entre los objetos y los conceptos, referenciando o nombrando, bien sea un objeto real o un objeto imaginario. De ahí que desde los estudios culturales tome fuerza la idea de la correlación entre los diferentes conjuntos de objetos y conceptos o representaciones mentales (por ejemplo, la muerte, el amor, la angustia, entre) como un sistema, ya que consiste, según Hall: «no en conceptos individuales, sino en diferentes modos de organizar, agrupar, arreglar y clasificar conceptos, y de establecer relaciones complejas entre ellos» (1997, p. 4). En este punto, el lenguaje llega a ser pensado como un sistema global y social en lo referente a la construcción de sentido. Y en la misma relación, y con la intención de clarificar o de unificar dichos sistemas, la lingüística ha optado por definir que el término para designar toda palabra, idea o imagen portadora de sentido es el signo, es decir, que los conceptos y las diferentes relaciones conceptuales conforman en su conjunto el sistema de sentido de nuestra cultura. Al respecto, Hall presenta un orden jerárquico en lo que él llama «sistemas relacionados de representación». El primer sistema consiste en «dar sentido al mundo mediante la construcción de un conjunto de correspondencias o una cadena de equivalencias entre las cosas — gente, objetos, eventos, ideas abstractas, etc.- - y nuestro sistema de conceptos, o mapas conceptuales» (1997, p. 6). El segundo sistema «depende de la construcción de un conjunto de correspondencias entre nuestro mapa conceptual y un conjunto de signos, organizados o arreglados en varios lenguajes que están por o representan esos conceptos» $(1997$, p. 6).

Del anterior sistema relacionado de representaciones se sigue consecuentemente el que la relación entre signos, conceptos y cosas den como resultado la producción de sentido dentro del lenguaje, es decir, las representaciones. Sin embargo, vale aclarar que tal reproducción de sentido dentro del lenguaje corresponde a una convención social que lo fija, y no a la naturaleza misma de la imagen, la cosa o la palabra, y de aquí se sigue también el que los sentidos producidos dentro del lenguaje, son así mismo producidos dentro de un contexto histórico y una cultura particular. Por lo tanto, no se fijan definitivamente sino que están sujetos a cambios y dependen de la 
dinámica de los tiempos, de ahí lo plural, lo mudable y lo dual del lenguaje y en él, sus desplazamientos, creaciones y recreaciones.

\section{Creación y recreación del lenguaje}

El lenguaje permite, según los planteamientos del apartado anterior, un proceso de cohesión social en cuanto a las convenciones de la producción de sentido por medio de las palabras y sus referencias directas, una vez establecidas, de lo que podría denominarse los objetos reales y los objetos imaginarios. En este sentido, en cuanto se entremezcla la relación del lenguaje con lo real y con lo imaginario, se pone de manifiesto, necesariamente, una división que es indispensable aclarar, a saber: qué son los objetos reales y cuáles los imaginarios, y ya para ir entrando en materia respecto al arte en general y la literatura y la poesía en particular, ¿cuál es la relación existente entre realidad y literatura? $\mathrm{O}$, ¿qué es la literatura y cuál es su relación con la realidad? Finalmente: ¿Cuáles son sus alcances y cuáles sus límites como representación?

Al intentar un acercamiento coherente a las preguntas planteadas, vale la pena acudir al historiador de la estética, Wladyslaw Tatarkiewicz, quien en Historia de seis ideas, y particularmente en el capítulo titulado "Mimesis: historia de la relación del arte con la realidad", nos propone un recorrido interesante sobre cómo ha sido ese camino de acuerdos y desacuerdos del arte para entenderse con la realidad y, a partir de allí, con sus propias posibilidades de creación y recreación.

Por lo limitado del espacio, no es posible hacer un recorrido por la evolución del tratamiento de la mimesis en la historia del arte; apenas podemos presentar una somera mención, con la intención de problematizar lo que desde la Antigüedad Clásica y la Edad Media entendieron por realidad en relación a las posibilidades que el arte tenía de entenderse con ella y así crearla, recrearla, tratarla o retratarla, mejorarla o deformarla, según el momento histórico y los materiales artísticos que se utilizaran.

Aristóteles afirmó que «el imitar es algo connatural a los seres humanos desde su niñez» (2003, p. 55) y para completar dicha aseveración anotó que «el hombre se distingue de los otros animales: en que es muy hábil en la imitación y su aprendizaje inicial se realiza por medio de la mimesis» (2003, p. 55). Estas observaciones que combinan aprendizaje e imitación, le valieron para presentar la tragedia como obra distintiva de una acción noble, en donde la mimesis no es una simple copia del original, sino que ella es la forma de ir más allá y representar las acciones y la vida de los hombres. Según él, lo significativo de la tragedia no son las expresiones que muestran los caracteres, sino que su estructura «tenga una fábula y una organización 
de los hechos» (2003, p. 65). La fábula es la mimesis de la acción y por medio de ella el espectador se reconoce a sí mismo. Lo importante no es la copia fácil y vacía de la realidad, sino la representación de circunstancias individuales con significación mayor a todos los individuos.

Para ampliar un poco las referencias históricas, vale la pena acudir al Władysław Tatarkiewicz, cuando rastrea el sentido de la representación artística y la concepción estética en sus diferentes momentos. Según nos dice, en la Antigüedad Clásica, la Edad Media y el siglo XVII, la realidad y sus posibles relaciones con el arte se limitaban, correspondientemente, a «percibir sólo lo que existe» (2007, p. 304), «limitarse al mundo visible» (2007, p. 304), y a dar «un parecido fidedigno» (2007, p. 309). Sin embargo, ya en el siglo XVIII, Edmund Burke, arremetía contra la poesía descriptiva justificando que esta no es imitación, pues «las palabras no se parecen a las cosas» (Tatarkiewicz, 2007, p. 309).

Lo anterior hay que entenderlo en relación al arte representativo del siglo XVIII, desde donde habla Burke, y no desde lo que va de él hasta el arte de las vanguardias y el arte abstracto contemporáneo, donde las condiciones entre el lenguaje como material de la poesía y el color y la piedra, como materiales de la pintura y de la escultura, respectivamente, cobran otras dimensiones, libertades y restricciones. Incluso en este mismo contexto, el ensayista Joseph Addison escribió en 1712, desde la revista The Spectator, algunas páginas para sumarse a la discusión estética, en donde la imaginación, tanto del artista como del espectador, tenía un papel preponderante. Él creía en un «nuevo» principio de placer unido esta vez al ánimo, es decir, a la recepción de la obra de arte como tal. En el ánimo del espectador y del artista ya no entraban en juego sólo los objetos representados como bellos y nuevos, sino también los desagradables, comunes, mezquinos y disformes a la imaginación. La apertura de Addison a estos elementos en ningún momento les da relevancia por encima de la belleza, incluso dice que a la imaginación le es «mucho más agradable lo grande, nuevo o bello: porque entonces no solo nos deleita con la comparación de la copia del original, sino también el original mismo» (1991, p. 188). Sin embargo, la inclusión de estos elementos en el relato o en la pintura se hace necesaria, según el autor inglés, para «representar aquellos objetos capaces de excitar una fermentación secreta en el ánimo del lector y mover fuertemente sus pasiones. En tal caso la descripción nos inflama y alumbra al mismo tiempo: el placer se hace más universal» (1991, p. 188). Lo interesante de estas líneas en este contexto es que ponen de manifiesto un matiz sensible en la lucha de contrarios presente en las manifestaciones artísticas, pues como el mismo autor lo dice, la belleza se suaviza con un aire de melancolía y de dolor cuando la poesía se esfuerza en excitar en sus lectores el terror y la compasión (1991, p. 189). 
Otro de los aportes que hace Joseph Addison en cuanto al tema de la realidad y su representación por medio del arte, es el de incluir las creaciones que están por fuera de la naturaleza y que entretienen la imaginación del artista, como lo son las brujas, las hadas, los magos, las hechiceras y los fantasmas o «almas separadas». Según él, «este estilo es, a la verdad, más difícil que otro cualquiera que depende de la fantasía del poeta: porque no tiene modelo alguno a quien seguir, y necesita obrar enteramente por su propia invención» (1991, p. 195). Esta inclusión en su compendio de ensayos titulado Los placeres de la imaginación, pone de manifiesto una apertura a la que no era ajena el arte y que con el tiempo le daría otras libertades a la creación e incluso a las necesidades del artista, como ocurriría más adelante con el Romanticismo y su relación directa con el sueño y con el inconsciente.

Así pues, la pintura del siglo XVIII, y lo que viene con ella, tiene un «parecido» con la realidad, pero también tiene libertad en su representación de las cosas mismas y del imaginario común, conservado por artistas y por poetas. El artista no se limita al mundo visible y a la semejanza «fidedigna» de lo representado. $Y$ en el mismo sentido, la poesía, a pesar de estar enmarcada dentro del lenguaje común —y este en el proceso de la producción de signos, conceptos y representaciones, dentro de una convención social, histórica y cultural — sigue conservando esa naturaleza dual. Así lo advertía Octavio Paz: «cada palabra encierra una pluralidad de sentidos [...] la palabra posee varios significados latentes, es una cierta potencialidad de direcciones y sentidos» (2011, p. 21). O la naturaleza multívoca de la que habla Gadamer (2006, p. 79) en relación con el lenguaje dentro de la estructura poética u obra de arte verbal.

Como es bien sabido, en el arte de la pintura o de la escultura, las diferentes técnicas habilitan al artista a representar fidedigna o figurativamente la imagen del modelo de turno, sea un paisaje, un animal o un objeto cualquiera. Los colores darán las sensaciones determinadas; los trazos, la forma y las expresiones; y el buril o el cincel, las texturas más cercanas a lo representado. Aquí pueden seguirse como ejemplos, entre los muchos posibles, las obras de Giovanni Antonio Canal, mejor conocido como Canaletto, en siglo XVIII, con sus pinturas de la ciudad de Venecia, que más parecen postales o fotografías de la época, o las obras del artista australiano Ron Mueck, como ejemplo del arte contemporáneo y sus esculturas en extremo realistas, salvo por las dimensiones dadas a los personajes retratados en sus esculturas.

En cuanto a la poesía, el panorama cambia radicalmente, pues en la pintura figurativa se puede comparar, en algunas ocasiones, el objeto que sirvió de inspiración o de modelo a lo representado (ya que tiene una semejanza real con el original); y cuando no es posible, pues igual, la imagen propuesta por el artista se impone como imagen, siendo identificables el «árbol», la «piedra» y el «río», por poner algunos ejemplos. Pero cuando aparecen en el poema y el «árbol», el «río» y la «piedra» 
son palabras y no imágenes impuestas, dichas imágenes, le pertenecen al lector en su forma de representárselas, al igual que con conceptos más complejos aún de ser representados, como lo pueden ser: el «amor», la «muerte», el «olvido», el «perdón», etcétera.

En el poema el lenguaje se presenta tan abierto que lo representado, a pesar de ligarse a unas ideas establecidas de significado y referencia, pertenece ahora a la idea personal que el lector tenga de cada una de ellas o logre representarlas para sí, según sus experiencias vitales, muy diferentes, quizás, a la que imaginó o vio el propio autor de un texto que las contenga. Lo que plantea Gadamer (2006) es importante y sirve aquí para abrir y problematizar el lenguaje y su participación en el texto poético:

La multivocidad de la poesía se entreteje inextricablemente con la univocidad de la palabra que mienta (meinendes Wort). Lo que sostiene esta tensísima interferencia es la particular posición del lenguaje respecto a todos los demás materiales con los que crea el artista: la piedra, la pintura, el sonido, e incluso el movimiento del cuerpo en la danza. Los elementos a partir de los cuales se construye el lenguaje y que se configuran en la poesía, son signos puros, que sólo en virtud de su significado (Bedeutung) pueden convertirse en elementos de la configuración poética. [...] La palabra con que se pronuncia y con la que él configura no se desprenderá nunca totalmente de su significado. Una poesía no objetual sería un balbuceo (p. 76).

Llama la atención el grado de importancia que le da Gadamer al lenguaje y a la configuración de la poesía, por medio de los signos y de los significados fijados socialmente. Ya antes se mencionaba, citando al mismo Gadamer y a Octavio Paz, la naturaleza dual y multívoca del poema, sin embargo, como se lee en la cita anterior, podría decirse que la palabra poética atiende no sólo a la naturaleza del lenguaje (en su configuración como producción de sentido social explicado arriba), sino también, y sobre todo, a la naturaleza del poema en su intención estética como obra de arte verbal. Aquí es válido recordar a Jorge Luis Borges, en su ensayo «La poesía», quien pensaba también el lenguaje como una creación estética y, a partir del lenguaje mismo, la poesía como su experiencia estética (2012, p. 269).

Ahora bien, al ser el lenguaje la materia prima del poema, queda claro que existe un significado gramatical que responde a lo objetual que nombra Gadamer y que hace posible que el solo hecho de nombrar un paisaje o la descripción de un viaje en un relato o en un poema, le permitan al lector seguir ese viaje o ese paisaje sin siquiera conocerlo, pues todos tenemos la imagen de lo que es un tren, un camino pedregoso, la caída del sol o una estación abandonada. Aun así, esa experiencia estética del lenguaje en el poema no se asume solamente desde el significado gramatical de la palabra que lo encerraría en su función meramente nominativa, explícita o de 
inventario, como decía Huidobro despectivamente en una conferencia de 1921 sobre la poesía (2003, p. 1296). El poema parte del lenguaje como referencia en su decir o nombrar algo, siempre vinculando al lector con el lenguaje, pero a su vez, creando en el poema líneas de fuga o de evasión de los límites nominativos del lenguaje, abriendo sus significados a partir de su forma ambigua de decir lo que dice. $\mathrm{O}$ citando nuevamente a Borges: «los versos son felices porque son ambiguos» (2012, p. 273). La ambigüedad «es la piedra de toque de la poesía: el verso existe más allá su sentido» (2012, p. 274).

Antes de cerrar este breve apartado, es necesario aclarar que no se desea en ningún momento dar una visión reduccionista del poema en favor de una definición fácil de lo que se propone hasta ahora, por lo tanto se rescata entonces esa naturaleza viva, radiante, libertaria y violenta de la poesía, de no sucumbir a las definiciones, parcelaciones ni encierros y nombrar aquí algunas (entre las muchas) propuestas poéticas de la experimentación, el juego y la vanguardia. Mencionemos las «Jitanjáforas» de Mariano Brull, la «Oración de la piedra» Vladimir Holan, los poemas pintados de Vicente Huidobro, los caligramas de Apollinaire y los «artefactos» de Nicanor Parra. Todos ellos haciendo del poema un campo fértil que no agota sus posibilidades en el lenguaje y que busca otros espacios de creación y de entendimiento en los límites del sonido, la musicalidad, el sinsentido, el hermetismo, la pintura o el dibujo.

Todo lo anterior podría ligarse al llamado que le hacía Luis Tejada a la poesía, desde la década de 1920, y que coincide en buena medida con lo que Terry Eagleton piensa del lenguaje literario:

¡Dios me guarde de los versos perfectos! Quiero los versos un poco descoyuntados, pero vivos y que vengan formados de palabras, no exóticas sino simplemente imprevistas; que envuelvan al mismo tiempo una idea o una imagen, no nueva, sino que apenas nos deje un poco atónitos, un poco sorprendidos, porque no la esperábamos allí, porque no adivinábamos que la estrofa iba a concluir de esa manera tan natural sin embrago, pero tan poco acostumbrada. No importa que todo eso no esté sujeto a las estrictas reglas métricas y no importa que el vocablo no sea demasiado elevado, demasiado poético. ¡Hay versos malos que son tan bellos! (Tejada, 1997, p. 40)

He aquí lo que podría ser otra definición del poema y de su particular relación con el lenguaje, en donde este se violenta o se deforma, convirtiendo así a la literatura en «una clase especial de lenguaje que contrasta con el lenguaje ordinario que generalmente empleamos» (Eagleton, 2009, p. 15). La violencia y la deformación del lenguaje que le asigna el crítico inglés a la literatura son cercanas a la que busca el cronista colombiano en la poesía de sus contemporáneos. Esto puede verse en las palabras y su sintaxis imprevista, así como la sorpresa, no sólo de lo que se dice 
sino de cómo se dice, y la relación natural del lenguaje con su sentido pero que va en contravía de las costumbres y de las buenas maneras, incluso de las autoimpuestas por el canon y las teorías literarias. En pocas palabras, es ese empleo característico de la lengua que no se limita ni siquiera a sí misma en busca siempre de nuevas posibilidades.

\section{EI lenguaje, constante deslizamiento}

Hasta el momento, y como acercamiento al poema y al lenguaje presente en él, con miras a pensar la relación de la poesía con la realidad, es posible volver sobre su referente objetual en el sentido práctico de su intención comunicativa, pero también, y con la intención de darle desde ya un espacio estético a esa configuración verbal que pretende ser obra de arte, es preciso volver sobre la naturaleza de la poesía, tanto en su proceso de creación como de recepción, en relación con lo que hasta ahora hemos llamado lenguaje dual, lenguaje ambiguo, lenguaje multívoco.

En este punto se puede olvidar el proceso de construcción del lenguaje que se exponía en apartados anteriores y que llevaba a comprenderlo desde una convención social que permite hablar y escuchar a los seres humanos de manera inteligible. Pero todavía más importante: las mismas convenciones que le permiten al autor no caer en el mero balbuceo del que habla Gadamer. O incluso aún más radical, como el mismo Stuart Hall lo plantea: «El autor decide lo que quiere decir. Pero no puede 'decidir' el usar o no usar las reglas del lenguaje, si es que de veras desea ser entendido. Nacemos dentro de un lenguaje, sus códigos y sentidos» (1997, p. 18). De aquí podría desprenderse entonces, el que el fenómeno social que es el lenguaje tenga una especial incidencia en el autor y en lo que escribe, es decir, en sus temas, en sus formas, sentimientos y en las palabras que escoge para decir lo que tiene que decir. Así mismo, dicha escogencia, al hablar de poesía o de literatura, va en dos direcciones, la ya mencionada por Hall y otra aún más compleja, que es la escogencia estética para componer el poema.

Respecto al lenguaje pensado como fenómeno social, es evidente también su mutación en el tiempo y lo que ello acarrea: el lenguaje no se fija bajo un solo código, sino que evoluciona y muta de sentido en sus referentes más complejos. Sírvanse como ejemplos pensar el cambio del imaginario que sobre el continente americano se tenía en el proceso de conquista y el imaginario que hay ahora sobre el mismo en este momento, o el significado de la palabra «pecado» en la Edad Media y en nuestros tiempos, también el uso (y el abuso) en palabras como «dios», «ocaso», «justicia», «nobleza»y un largo etcétera de referencias y significados que se reevalúan con el 
tiempo y a los que el poeta quizá sea el primer llamado a «poner en situación», ${ }^{2}$ como lo planteaban ya en 1955 los intelectuales colombianos reunidos en la revista Mito.

El juego de desplazamientos en los significados del lenguaje es el que le brinda, a su vez, y con artificios propios de la poesía, como lo son la metáfora, el símil y el hipérbaton (por mencionar algunos), al poema su naturaleza dual, ambigua y multívoca. Y de aquí se sigue, claro está, la producción de nuevos sentidos, de nuevas interpretaciones, en donde la participación del lector es tan importante como la del autor. Por este motivo la «multivocidad de la palabra poética corresponde plenamente a la multivocidad del ser humano» (Gadamer, 2006, p. 79).

Lo que se sigue de esta relación de la palabra no es el que todo lo que se diga sea ambiguo, ni mucho menos. En el lenguaje hablado como en el escrito, existen tanto las posibilidades de lo unívoco como de lo multívoco, es decir, lo que remite a una idea, acción u orden sin ninguna vacilación o interpretación posible sino que se ciñe al mensaje dado, o lo que se abre a interpretaciones varias y que en ningún momento se cierran sobre un solo significado. De aquí se desprende que dicha naturaleza del lenguaje recaiga únicamente en su uso, no en la escogencia de las palabras sino en su disposición para ser utilizadas, escritas o dichas. Pues finalmente el lenguaje o, mejor aún, las palabras, como se ha venido insistiendo, son las mismas en lo cotidiano como en la literatura. No existe un lenguaje poético y otro no poético en el sentido estricto de la palabra, sobre todo cuando nos acercamos a la poesía contemporánea y pensamos en Rimbaud, Baudelaire, Pablo de Rokha o José Asunción Silva.

Ya para ir cerrando este apartado y con la intención de abrir el espacio a las siguientes discusiones, vale la pena volver sobre lo que en líneas anteriores se mencionaba respecto a la mutación del lenguaje en el tiempo y el deslizamiento de sus significados. Para ello viene muy bien una cita de Fernando Charry Lara (2005), en donde queda claro que el poeta no ignora los diferentes desplazamientos de sentido, y que al contrario, es él quien representa la salud y la vivacidad de la lengua, siempre volviendo la mirada atenta sobre lo que dice y cómo lo dice:

Toda revolución poética pretendería, una vez pasado de moda el lenguaje utilizado por una generación precedente, el regreso a ese idioma cotidiano del tiempo nuevo. Lenguaje cotidiano, lenguaje ordinario que expresa, con toda su vivacidad, al hombre de una época. Es este idioma el que busca para su verso el poeta y no el que le llega de la anterior creación literaria, el cual, al deslustrarse con el uso, ha perdido su virtud

2 La expresión que recoge Armando Romero, y que pertenece al número 1 de la revista Mito, mayo de 1955 , es la siguiente: «Las palabras están en situación. Sería vano exigirles una posición unívoca, ideal» (Romero, 1985, p. 120). La cita en la revista aparece sin firma y es, como dice Romero, una «declaración de principios» (1985, P. 120) de la dirección de la revista, en cabeza de Jorge Gaitán Durán y Hernando Valencia Goelkel. 
significativa. Sabemos, como consecuencia, que es deber de toda generación literaria encontrar su propio lenguaje (p. 137).

E1 llamado que hace Charry Lara en 1959 pertenece al ensayo titulado "La crisis del verso en Colombia" y pone de relieve lo que se viene mencionando: el lenguaje cotidiano y el lenguaje ordinario, en suma, el Lenguaje con mayúscula. Es decir, el lenguaje como entidad viva de la que bebe el poeta. Y como se expone en el texto, no existe un lenguaje meramente poético o destinado para escribir poesía. Cada época, cada generación de poetas, sopesa el lenguaje que le ha tocado en préstamo y es así como se revitaliza la palabra y en ella su significado, su querer decir, ampliando con ello las posibilidades para comunicarlo.

En su ensayo «Sobre poética y hermenéutica», escrito en 1971, Gadamer ya planteaba también ese otro reto de la poesía y del poeta, de tener que entenderse con el lenguaje que ha sido pensado con una univocidad pragmática y sobrepasar esos límites para rescatar la polivalencia propia de la palabra y así llegar al poema, rescatando que en la poesía moderna, y ella misma en diálogo con el arte contemporáneo, ha dejado de lado la idea de belleza y perfección, de gusto y refinamiento, haciendo posible, y aún necesario, el entenderse con el lenguaje que roza los límites con lo escatológico, lo prosaico y lo grotesco (2006, p. 99). El reto entonces está en que el poema sobrepase, en su conformación verbal, esa «univocidad simplemente brutal» (Gadamer, 2006, p. 99), es decir, que tome del lenguaje inmediato y común, con el que todos nos comunicamos cotidianamente, para lograr con él un poema que no agote la comprensión y el sentido, que no se cierre en sí mismo como una conversación directa.

\section{Mimesis: entre la ficción y la verosimilitud}

Cuando se habla de literatura en general y de poesía en particular, como es el caso de este artículo, se coincide con la idea de que el arte de la poesía es el lenguaje, es decir, que la poesía se presenta como el resultado estético del lenguaje. Y en él, como se presentó unas líneas más arriba, el lenguaje como material de la obra opera diferente al de las demás manifestaciones artísticas, sobre todo al reducirlas a lo representativo o figurativo, pues en ellas es dada la comparación con el objeto visible. En la poesía, al contrario, no hay comparación posible con lo representado, sino que las palabras presentes en ella pasan de inmediato a la configuración de un mundo que, aun partiendo de un referente directo de la palabra que nombra, no se queda ahí sino que va mucho más allá creando uno propio. Algo muy cercano a lo propuesto por Gadamer en su ensayo titulado «Poesía y mimesis», en el que intenta dos definiciones que ahora nos sirven de apoyo para continuar: el poeta es quien 
hace «existir a algo nada más que con palabras» y la poesía es «algo que es 'hecho' de tal modo que no tiene otro sentido que el de hacer ser ahí. Lo que una obra de arte sea, en cuanto obra lingüística, no tiene que estar ahí en consideración hacia nada» (Gadamer, 2006, pp. 125-126). Lo anterior sirve de soporte para exponer la problemática mencionada en el sentido en que es la palabra la que articula esa «nueva» configuración de mundo, que pende entre el significado referencial u objetual y la nueva disposición estética que el poeta se apropia para sí y lo comparte con sus lectores. Las palabras, después de pasar por un complejo constructo social, ya van cargadas de sentido, y siempre y cuando no se salgan de esa convención en que fueron creadas, ya están poniendo algo ante sí. Sin embargo, ese hecho estético que llamamos poesía se configura de tal manera autónomo, que vale por sí mismo independiente de si es o no una descripción de lo «real» visible, de lo «existente» por los sentidos o si se «parece» a algo. El poema así pensado, es entonces un nuevo mundo sometido a la palabra que lo crea, siempre dentro de unas lógicas que tienen como intención estética, no la de crear o recrear la realidad, sino más bien la de sumar otras realidades posibles dentro del texto literario o del poético, a la realidad pensada como la experimentada por los sentidos. En este punto podría pasarse a hablar directamente sobre esos tres conceptos claves que ayudarán a articular lo expuesto hasta ahora: mimesis, ficción y verosimilitud.

La poesía, según la perspectiva hasta aquí expuesta, se ha asumido como un hecho estético que toma del constructo social que es lenguaje, su materia prima para desarrollarse como obra de arte. Según esto, ese uso del lenguaje que se ha denominado hecho estético, marca de por sí una brecha enorme entre el uso cotidiano, conversacional y referencial del lenguaje como comunicación y lo eleva a otras características que lo diferencian radicalmente. La primera de ellas, o más bien, su primera consecuencia, es la correspondencia que el lenguaje toma en el poema en relación con la realidad, o lo que es lo mismo, con su primera función pragmática, pues de ello se entiende el que toda obra de arte lingüística, como la nombra Gadamer, sea en mayor o en menor medida, una transformación de la realidad.

El hispanista alemán Kurt Spang ha ahondado un poco en este fenómeno, en donde para él la realidad, y en ella el lenguaje que la nombra, hacen parte de un mismo juego de adhesión y de transgresión unidos a lo humano:

Al afirmar que toda creación literaria implica necesariamente la plasmación de una realidad humana y material, me refiero al hecho de que toda literatura trata del hombre en una situación espacio temporal. Digo necesariamente porque hasta la imaginación más desbordante arranca de realidades reales; y ello por la simple razón de que no disponemos de otro mundo, tanto el autor como el lector de la obra literaria. Hasta la invención 
más desorbitada sólo es distinta en función de lo existente, se crea y se recibe con el instrumental que suministra nuestra realidad (Spang, 1984, p. 153).

La cita de Spang pone como factor relevante la «realidad humana y material», es decir, todo lo que circunda al hombre y que aprehende por sus sentidos. Y aquí volvemos sobre dos palabras clave que se nombraban al principio: lo real y lo imaginario. Ambas, claro está, mediadas por el lenguaje. En cuanto a lo real lo dejaremos por ahora, pues ya se han presentado algunos elementos para tratarlo, pero en cuanto a la imaginación vale la pena ampliar su problematización con una cita de Jean Starobinski para seguir discutiendo la propuesta de Spang:

La imaginación es mucho más que una facultad de evocar imágenes que duplicarían el mundo de nuestras percepciones directas: es un poder de desviación gracias al cual nos representamos las cosas distantes y nos distanciamos de las realidades presentes. La imaginación [...] dibuja frente a nosotros la configuración realizable antes de que se realice. [...] Exige que salgamos del instante presente, que superemos los datos del mundo inmediato [...] lejos de contribuir a la "función de lo real" aligera nuestra existencia (Starobinski, 2008, p. 143-144).

Para seguir con Spang y con Starobinski, es necesario recordar el que el enfoque dado aquí a la discusión por el lenguaje y su sistema de representaciones se agrupa dentro de lo planteado por Stuart Hall. Es decir, siguiendo la misma lógica, el constructo que llamamos imaginación también está mediado por el lenguaje y que la palabra que «imagina», referencia o designa un objeto imaginario (llámese ángel, monstruo, hada, unicornio, infierno, dios, etcétera), no es más que el resultado de representaciones mentales concertadas bajo un conjunto de correspondencias fijadas cultural y socialmente, lo cual no quiere decir que el mundo «material» sea el único portador de sentido por la referencialidad con el objeto como única posibilidad del lenguaje. No obstante, y aquí sí de acuerdo con Spang, en la dirección de que las correspondencias atribuidas a los objetos, conceptos o ideas imaginadas o abstractas sí parten de su relación con las «realidades reales», pues dichas realidades-referentes, son la base instrumental para imaginar. En este punto sirve como ejemplo pensar los atributos que conforman cada uno de los ejemplos mencionados unas líneas arriba (ángel, monstruo, hada, unicornio, infierno, dios), en relación con los posibles referentes reales de donde se tomó para su fijación en la imaginación y nos encontraríamos con conceptos más elevados y elaborados como los de justicia, bondad y maldad, belleza y espanto, armonía y simetría, por no mencionar características físicas atribuidas a cada uno de ellos, también salidas de las convenciones sociales que acompañan sus particulares comportamientos, significados e idealizaciones. En cuanto a la postura de Starobinski sobre la imaginación, la impresión que deja es 
más bien la de una defensa que la de una definición. Dicho esto en el mejor de los sentidos, pues el autor nos lleva sensiblemente a la imaginación, a sus posibilidades y alcances y, por tanto, a la literatura misma.

Una vez establecidas las dos definiciones de lo real y de lo imaginario, aparecen otros dos conceptos importantes para la creación literaria que también nombra Spang (1984, pp. 153-154): la mimesis, entendida como los recursos imitativos, y la ficción, entendida a su vez como los recursos inventivos. Ambos unidos indisolublemente, como lo acabamos de mostrar, con lo real y con lo imaginario, a la realidad, pues ambas, mimesis y ficción, encuentran en ella, por diversos medios y con diferentes intenciones, el material necesario para la escritura del texto. Y dentro de este material, un tercer elemento que articula los dos primeros: la verosimilitud, es decir, ese elemento tanto formal como estético que le sirve de regulador al autor para que lo escrito por él sea creíble en el texto, o lo que es lo mismo, que lo escrito se presente como posible, como ficción posible dentro de los elementos que lo constituyen.

\section{Coda}

Con la idea de mimesis viene otra acepción de la representación, diferente a como la hemos tratado hasta ahora, pero que se complementan ambas para llegar a comprender mejor la relación de la poesía con la realidad. Aquí volvemos nuevamente a Kurt Spang: «La mimesis de la praxis nunca es reproducción y reflejo servil de la realidad, sino representación de circunstancias individuales (ficticias o no) en la que se resalta la significación y validez universal» (1984, p. 156). Eso lo justifica el autor hablando precisamente de la tragedia griega, en el sentido de que esta tiene un valor estético no sólo por la composición escrita o la interpretación escogida por el actor, sino en la medida en que sobrepase una «problemática dramatización individualizada» y se extienda su representación a todos los individuos haciéndose universal. Y acá tenemos nuevamente el vínculo de la imaginación con las «realidades reales» que la aterrizan a lo humano y, por ello a la realidad, es decir, tanto la mimesis como la ficción encuentran en la realidad sus elementos de configuración estética, con la diferencia de que la ficción, y en ella la poesía, se toma libertades mayores que la imitación no puede permitirse.

\section{Referencias bibliográficas}

1. Addison, J. (1991). Los placeres de la imaginación y otros ensayos de The Spectator. Madrid: Visor, La balsa de la Medusa, Clásicos.

2. Aristóteles. Horacio. (2003). Artes poéticas. Madrid: Visor libros. Edición bilingüe de Aníbal González. 
3. Borges, J. L. (2012). Selección cuentos, ensayos y poemas. Medellín: Universidad de Antioquia.

4. Charry Lara, F. (2005). Lector de poesía y otros ensayos. Bogotá: Mondadori.

5. Eagleton, T. (2009). Una introducción a la teoría literaria. México: Fondo de Cultura Económica.

6. Gadamer, H. G. (1993). Gesammelte Werke. Band 8. Ästhetik und Poetik. 1. Kunst als Aussage. Tübingen: Mohr Siebeck

7. Gadamer, H.G. (2006). Estética y hermenéutica. Madrid: Editorial Tecnos.

8. Hall, S. (1997). El trabajo de la representación. En: Stuart Hall (ed.), Representation: Cultural Representations and Signifying Practices. London, Sage Publications, Cap. 1, pp. 13-74. Traducido por Elías Sevilla Casas. Versión digital tomada el 05/04/2015 de: https://archive.org/stream/ pdfy_chKTwaEs_TTEn9/14_El_trabajo_de_la_representacion_Stuart_Hall_djvu.txt

9. Huidobro, V. (2003). Obra poética. Francia: Colección archivos.

10. Romero, A. (1985). Las palabras están en situación. Bogotá: Procultura.

11. Paz, O. (2011). El arco y la lira. México: Fondo de Cultura Económica.

12. Spang, K. (1984). Mimesis, ficción y verosimilitud en la creación literaria. En: Anuario filosófico, Vol. 17, No 2, pp. 153-159.

13. Starobinski, J. (2008). El ojo viviente II. La relación de la crítica. Buenos Aires: Ediciones Nueva Visión.

14. Tatarkiewicz, W (2004). Historia de seis ideas: arte, belleza, forma, creatividad, mimesis, experiencia estética. Madrid: Tecnos - Aliaza.

15. Tejada, L. (1997). Libro de crónicas. Bogotá: Editorial Norma. 